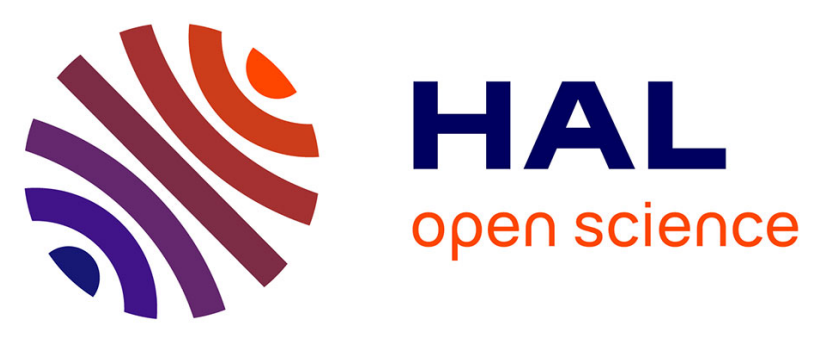

\title{
Coumarin Derivatives as Photoinitiators in Photo-oxidation and Photo-reduction Processes and Kinetic Model for Simulations of the Associated Polymerization Profiles
}

Mira Abdallah, Akram Hijazi, Jui-Teng Lin, Bernadette Graff, Frederic

Dumur, Jacques Lalevee

\section{To cite this version:}

Mira Abdallah, Akram Hijazi, Jui-Teng Lin, Bernadette Graff, Frederic Dumur, et al.. Coumarin Derivatives as Photoinitiators in Photo-oxidation and Photo-reduction Processes and Kinetic Model for Simulations of the Associated Polymerization Profiles. ACS Applied Polymer Materials, 2020, 2 (7), pp.2769-2780. 10.1021/acsapm.0c00340 . hal-02895865

\section{HAL Id: hal-02895865 https://hal.science/hal-02895865}

Submitted on $20 \mathrm{Jul} 2020$

HAL is a multi-disciplinary open access archive for the deposit and dissemination of scientific research documents, whether they are published or not. The documents may come from teaching and research institutions in France or abroad, or from public or private research centers.
L'archive ouverte pluridisciplinaire HAL, est destinée au dépôt et à la diffusion de documents scientifiques de niveau recherche, publiés ou non, émanant des établissements d'enseignement et de recherche français ou étrangers, des laboratoires publics ou privés. 


\title{
Coumarin Derivatives as Photoinitiators in Photo-oxidation and Photo- reduction Processes and Kinetic Model for Simulations of the Associated Polymerization Profiles
}

\author{
Mira Abdallah ${ }^{1,2,3}$, Akram Hijazi $^{3}$, Jui-Teng Lin ${ }^{4}$, Bernadette Graff ${ }^{1,2}$, Frédéric Dumur*5, Jacques \\ Lalevée*1,2 \\ ${ }^{1}$ Université de Haute-Alsace, CNRS, IS2M UMR 7361, F-68100 Mulhouse, France \\ ${ }^{2}$ Université de Strasbourg, 67000 Strasbourg, France \\ ${ }^{3}$ EDST, Université Libanaise, Campus Hariri, Hadath, Beyrouth, Lebanon \\ ${ }^{4}$ Photon Vision, Corp; 10F, No. 55, Sect. 3, Xinbei Blvd, Xinzhuang, New Taipei City 242, \\ Taiwan \\ ${ }^{5}$ Aix Marseille Univ, CNRS, ICR UMR 7273, F-13397 Marseille, France
}

Corresponding author: Frederic.dumur@univ-amu.fr*; jacques.lalevee@uha.fr*

\begin{abstract}
In this work, the design of an original series of coumarin derivatives (CoumC1-CoumC13) is presented. Chemical structures of these coumarins were selected by molecular modelling to ensure both excellent light absorption properties and high potential photoreactivity (high excited state energy). As a striking result of this in-silico design, 8 of the 13 proposed coumarins were never presented and were specifically proposed for this work, evidencing the interest of the structures. New multi-component photoinitiating systems (PISs) based on these coumarins are proposed for the free radical polymerization (FRP) of (meth)acrylates and examined upon visible light irradiation using the light emitting diode (LED) as a safe and economical irradiation source. The proposed systems are based on coumarins which act as remarkable photoinitiators/photosensitizers (PIs/PSs) combined with $N$-phenylglycine (NPG) and/or iodonium salt (Iod) as co-initiators in order to generate the reactive species (radicals) that will initiate the photopolymerization recation. Investigation of the chemical mechanisms suggested by the different interactions that take place as well as the photophysical and photochemical properties of coumarins are provided. The access
\end{abstract}


to high polymerization rates ( $\mathrm{Rp}$ ), excellent photoinitiating abilities and great reactive function conversions (FC) is possible with these structures based on the coumarin core. Coumarins show high efficiency for the FRP of (meth)acrylates by reaction with iodonium salt (a photo-oxidation process) or with amine (a photo-reduction process). These compounds were used in 3D printing resins but also for the preparation of photocomposites. In this latter case, an excellent depth of cure was noted as remarkable behavior. To rationalize the experimental results, a kinetic model for a three-component system has been established to analyze the role of oxygen in the monomer conversions and the conversion enhancement observed while using an amine as a co-initiator.

KEYWORDS: Coumarin; photocomposite; photoinitiator; 3D polymer patterns; photopolymerization; simulation.

\section{INTRODUCTION}

Effective fluorescent organic heterocyclic molecules include coumarins which are characterized by very interesting properties starting from their high electron transfer quantum yields [1] to the capability of their excited states to react as electron donors or acceptors [2], their extended spectral range and their good solubility [3] and so on. These latter properties make them a point of interest for different uses such as sensitizers for solar energy collectors [4], fluorescent probes [5], sensors [6] and dopants for organic light emitting diodes [7]. It should be noted that different areas ranging from photochemistry to photonics and photobiology [8-12] have been interested in using coumarins owing to their remarkable photophysical properties. Coumarins can also react as anti-bacterial [13], anti-cancer [14] and anti-coagulant [15] agents showing again their importance in the pharmacological field. The use of some coumarin derivatives which absorb in the UV region for emulsion polymerization in order to obtain labeling latex particles, their 
synthesis and also their characterization have been reported in [16]. Otherwise, coumarin moieties have been used by fixing them covalently onto a Mn-Anderson Cluster in order to prepare a new polyoxometalate (POM) which can undergo reversible polymerization [17]. In addition, coumarin derivatives combined with diphenyliodonium hexafluorophosphate have been used for the twophoton microstructure-polymerization as published in $[18,19]$.

Several usages of coumarin derivatives have been already mentioned in photoinitiating systems (PISs) according to the literature [18,20-24]. Interestingly, our recently published papers report on the use of many coumarin derivatives designed as photoinitiators or as photoredox catalysts (PIs/PCs) to initiate both the free radial polymerization (FRP) of (meth)acrylates and the cationic polymerization of epoxides upon exposure to light emitting diode (LED) at $405 \mathrm{~nm}$ as a foolproof and low-cost irradiation source. Their outstanding photoinitiating abilities were used for the generation of 3D patterns but also for the preparation of photocomposites [20-22]. Remarkably, we were also able to use coumarin derivatives for photopolymerization processes done in water in order to prepare hydrogels which are very required for biomedical applications [20].

In the present study, a new set of coumarin derivatives (CoumC1-CoumC13; Figure 1) has been in silico designed and investigated as visible light photoinitiators (PIs) for the polymerization (FRP) of (meth)acrylates. To ensure a high reactivity, the structures were first proposed by molecular modelling (in silico design) to optimize their light absorption @405 nm (see the predicted absorption properties below) and high excited state energy (to ensure potential electron transfer processes from these excited states). The most interesting structures were selected for synthesis. This rationale approach is highly worthwhile i.e. 8 never synthesized coumarins have been specifically designed here. 
Two different initiating systems were developed with these compounds: a combination with iodonium (a photo-oxidation process) as the co-initiator $(\operatorname{Coum} / \mathrm{Iod}(0.2 \% / 1 \% \mathrm{w} / \mathrm{w}))$ and also a photo-reduction process in which coumarins are combined with an amine (EDB, NPG) (Coum/EDB or NPG $(0.2 \% / 1 \%$ w/w)). Three-component (Coum/NPG/Iod) photoinitiating systems (PISs) are also studied for the FRP of (meth)acrylates. In order to unambiguously propose the interactions in their excited states, a full global photochemical mechanism is supplied. Additional techniques (fluorimetry, UV-visible spectroscopy, electron spin resonance (ESR) and cyclic voltammetry $(\mathrm{CV})$ ) are used to determine the fundamental photophysical properties of the different coumarins. A kinetic model for a three-component system is presented, for the first time, to demonstrate the role of oxygen inhibition and the amine enhancer. More precisely, a numerical model and analytic formulas were developed to analyze the function conversion trends of measured results.

To evidence the high reactivity of the different coumarins, applications of these dyes in 3D printing photosensitive resins or for photocomposites are presented. 

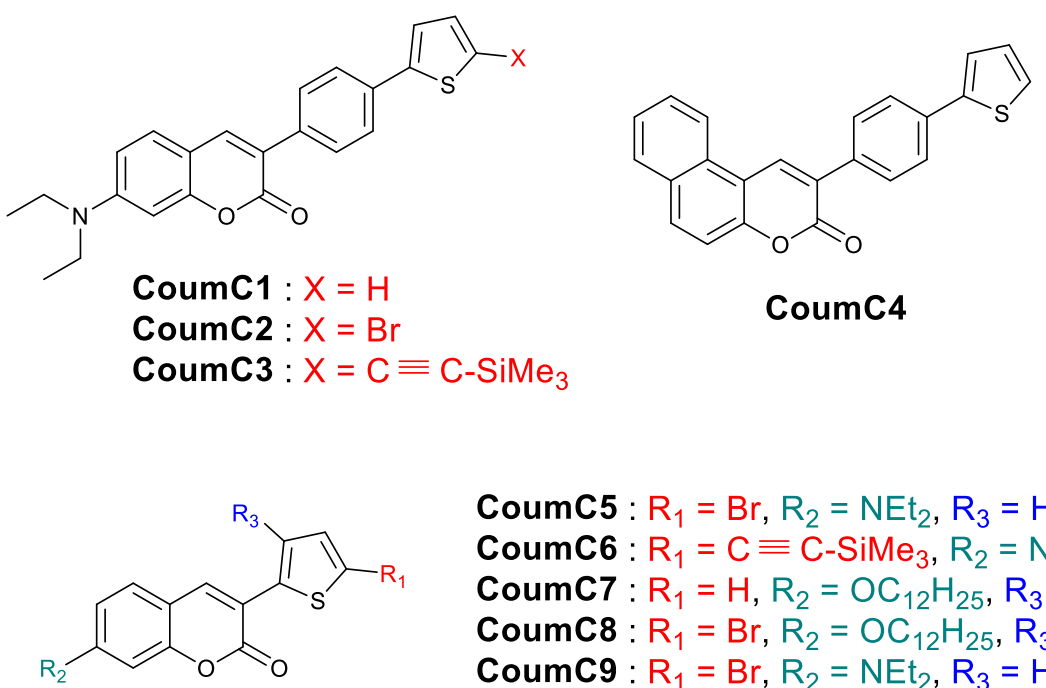

$$
\begin{aligned}
& \text { CoumC5 }: \mathrm{R}_{1}=\mathrm{Br}, \mathrm{R}_{2}=\mathrm{NEt}_{2}, \mathrm{R}_{3}=\mathrm{H} \\
& \text { CoumC6 }: \mathrm{R}_{1}=\mathrm{C} \equiv \mathrm{C}-\mathrm{SiMe}_{3}, \mathrm{R}_{2}=N \mathrm{Nt}_{2}, \mathrm{R}_{3}=\mathrm{H} \\
& \text { CoumC7 }: \mathrm{R}_{1}=\mathrm{H}, \mathrm{R}_{2}=\mathrm{OC}_{12} \mathrm{H}_{25}, \mathrm{R}_{3}=\mathrm{H} \\
& \text { CoumC8 }: \mathrm{R}_{1}=\mathrm{Br}, \mathrm{R}_{2}=\mathrm{OC}_{12} \mathrm{H}_{25}, \mathrm{R}_{3}=\mathrm{Br} \\
& \text { CoumC9: } \mathrm{R}_{1}=\mathrm{Br}, \mathrm{R}_{2}=\mathrm{NEt}_{2}, \mathrm{R}_{3}=\mathrm{H} \\
& \text { CoumC10 }: \mathrm{R}_{1}=\mathrm{Br}, \mathrm{R}_{2}=\mathrm{OH}, \mathrm{R}_{3}=\mathrm{H} \\
& \text { CoumC11 }: \mathrm{R}_{1}=\mathrm{Ph}-\mathrm{CHO}, \mathrm{R}_{2}=\mathrm{NEt}_{2}, \mathrm{R}_{3}=\mathrm{H}
\end{aligned}
$$

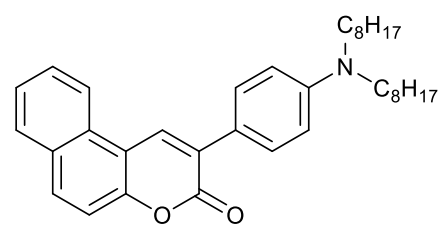

CoumC12

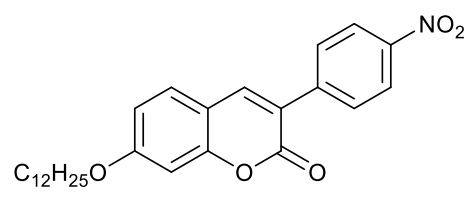

CoumC13

Figure 1. Structures of the different coumarins.

\section{EXPERIMENTAL PART}

\subsection{Synthesis of the Coumarins}

Synthesis of the different coumarins are depicted in the Figure 1 and detailed in supporting information (SI) (Figures S1-S6).

\subsection{Other Chemicals}

Di-tert-butyl-diphenyl iodonium hexafluorophosphate (Iod or SpeedCure 938) from Lambson Ltd, $\mathrm{N}$-Phenylglycine (NPG), ethyl 4-(dimethylamino)benzoate (EDB), bisphenol Aglycidyl methacrylate (BisGMA) and triethyleneglycol dimethacrylate (TEGDMA) from Sigma 
Aldrich. Trimethylolpropane triacrylate (TMPTA) was a gift from Allnex. As benchmark monomers, TMPTA and BisGMA/TEGDMA were selected (See Scheme 1).

\subsection{Light Sources}

LEDs emitting at $375 \mathrm{~nm}$ and $405 \mathrm{~nm}$ were selected $\left(\mathrm{I}_{0}=40 \mathrm{~mW} . \mathrm{cm}^{-2}\right.$ and $\mathrm{I}_{0}=110 \mathrm{~mW}$. $\mathrm{cm}^{-2}$, respectively).

\subsection{Real-Time (RT)-FTIR to Follow Polymerization Kinetics}

In this research, two and three-component photoinitiating systems (PISs) were studied for the FRP of (meth)acrylates. Coumarin/NPG (or Iod or EDB) $(0.2 \% / 1 \% \mathrm{w} / \mathrm{w}$ ) and and Coumarin/NPG/Iod $(0.2 \% / 1 \% / 1 \%$ w/w) systems were used as two-component PISs and threecomponent PISs, respectively. The weight percent given is calculated based on the monomer content $(\mathrm{w} / \mathrm{w})$. For the FRP of acrylates (thin samples, thickness $=25 \mu \mathrm{m}$ ) in laminate conditions, polypropylene films were used to reduce $\mathrm{O}_{2}$ inhibition. Evolution of the double bond content of the reactive acrylate function was monitored at $1630 \mathrm{~cm}^{-1}$ by RT-FTIR spectroscopy (JASCO FTIR 4100). For thick samples, a mold was used to control the thickness $(1.4 \mathrm{~mm})$ and the double bond conversion was followed at $\sim 6160 \mathrm{~cm}^{-1}$. All these procedures have been already described in detail in [25-27].

\subsection{Redox Potentials Calculation for the Access to the Free Energy Change}

By using cyclic voltammetry, the oxidation and reduction potentials $\left(\mathrm{E}_{\mathrm{ox}}\right.$ and $\left.\mathrm{E}_{\mathrm{red}}\right)$ of the different compounds were studied. By applying the classical equation 1 (eq. 1) [28], the free energy change $\left(\Delta \mathrm{G}_{\mathrm{et}}\right)$ for the electron transfer reaction could be determined.

$$
\Delta G_{\text {et }}=E_{\text {ox }}-E_{\text {red }}-E^{*}+C
$$




\subsection{Electron Spin Resonance - Spin Trapping (ESR-ST) Experiments}

ESR-ST experiments were realized using an X-Band spectrometer (Magnettech MS400) under $\mathrm{N}_{2}$ in tert-butylbenzene as the solvent; the free radicals generated upon irradiation were trapped by phenyl- $N$-tert-butylnitrone (PBN) (spin trapping agent), using a protocol previously reported in the literature [26,27]. Simulations for the ESR spectra were obtained using the PEST WINSIM program.

\subsection{UV-visible Absorption and Photolysis Experiments}

A JASCO V730 UV-visible spectrometer was used to perform the steady state photolysis experiments as well as the absorption properties of the different coumarins.

\subsection{Fluorescence properties}

Fluorescence properties were examined using a JASCO FP-6200 spectrofluorimeter. The same machine was used for the fluorescence quenching experiments of the different coumarins.

\subsection{Computational Procedure}

Theoretical calculations was performed using the Density Functional theory; the procedure is presented in [29].

\subsection{D Patterns}

3D printing experiments were carried out using a laser diode at $405 \mathrm{~nm}$ (spot size of $50 \mu \mathrm{m}$ ) controlled by a computer, enabling to generate the desired 3D patterns. These patterns were characterized using a numerical optical microscopy (DSX-HRSU from OLYMPUS Corporation) $[30,31]$.

\subsection{Near-UV Conveyor}


The Dymax conveyor (LED @395 nm; 4W/cm²) was utilized to cure composites prepared by impregnation of the glass fibers with the appropriate organic resin $(50 \% / 50 \% \mathrm{w} / \mathrm{w})$.

\section{RESULTS AND DISCUSSION}

\subsection{Light Absorption Properties of the Investigated Compounds}

$\mathrm{UV}$-visible absorption spectra of the different coumarins were examined in acetonitrile, as shown in Figure S7 (see also in Table 1). It is well obvious from the results that coumarin derivatives possess high molar extinction coefficients $(\varepsilon)$ in the near-UV and the visible range e.g. $\boldsymbol{\varepsilon}($ CoumC3 $)=48600 \mathrm{M}^{-1} \cdot \mathrm{cm}^{-1}$ at $\lambda_{\max }=411 \mathrm{~nm}, \boldsymbol{\varepsilon}($ CoumC11 $)=48500 \mathrm{M}^{-1} \cdot \mathrm{cm}^{-1}$ at $\lambda_{\max }=457 \mathrm{~nm}$. As a result of this, a good superimposition of the emission spectra of the light sources with the absorption spectra of the coumarins is expected due to the intense absorptions of the coumarin derivatives in the whole 280-560 spectral range.

A selection of the frontier orbitals determined for a series of coumarins is presented in Figure S8. Both the highest occupied molecular orbital (HOMO) and the associated lowest unoccupied molecular orbital (LUMO) extend over the $\pi$-conjugated system in agreement with a low energy HOMO-LUMO gap. $\pi \rightarrow \pi^{*}$ lowest energy transitions are also observed with a partial charge transfer character (HOMO and LUMO being localized on different place).

Table 1. Optical Properties of the Coumarins.

\begin{tabular}{|c|c|c|c|}
\hline PI & $\lambda_{\max }(\mathrm{nm})$ & $\varepsilon_{\max }\left(M^{-1} \cdot \mathrm{cm}^{-1}\right)$ & $\varepsilon_{@ 405 \mathrm{~nm}}\left(\mathrm{M}^{-1} \cdot \mathrm{cm}^{-1}\right)$ \\
\hline CoumC1 & 407 & 42400 & 42300 \\
\hline CoumC2 & 408 & 41700 & 41600 \\
\hline CoumC3 & 411 & 48600 & 48000 \\
\hline CoumC4 & 372 & 26200 & 10200 \\
\hline
\end{tabular}




\begin{tabular}{|c|c|c|c|}
\hline CoumC5 & 432 & 29500 & $\mathbf{2 0 9 0 0}$ \\
\hline CoumC6 & 445 & 34400 & $\mathbf{1 6 9 0 0}$ \\
\hline CoumC7 & 367 & 25800 & $\mathbf{8 4 0 0}$ \\
\hline CoumC8 & 361 & 23000 & $\mathbf{6 1 0 0}$ \\
\hline CoumC9 & 421 & 32800 & $\mathbf{2 8 4 0 0}$ \\
\hline CoumC10 & 355 & 11300 & $\mathbf{7 0 0}$ \\
\hline CoumC11 & 457 & 48500 & $\mathbf{1 7 3 0 0}$ \\
\hline CoumC12 & 416 & 21100 & $\mathbf{2 0 2 0 0}$ \\
\hline CoumC13 & 361 & 25600 & $\mathbf{6 2 0 0}$ \\
\hline
\end{tabular}

\subsection{Free Radical Photopolymerization of Acrylates (TMPTA)}

Different combinations based on coumarins (Coum/NPG, Coum/Iod or Coum/EDB $(0.2 \% / 1 \% \mathrm{w} / \mathrm{w})$ and Coum/NPG/Iod $(0.2 \% / 1 \% / 1 \% \mathrm{w} / \mathrm{w}))$ have been tested for the FRP of TMPTA in thin films $(25 \mu \mathrm{m})$. High final acrylate function conversions (FCs) and rate of polymerization (Rps) are shown for the different coumarins while using the different photoinitiating systems (PISs) (Figures 2,3, Table 2). It has to be noticed that coumarins, Iod, NPG or EDB examined separately are unable to initiate the FRP of TMPTA under the same conditions, clearly showing that the presence of the coumarins was required for an efficient process.

When the iodonium salt is combined with coumarin derivatives, a good efficiency is found in terms of FC and Rp as shown in Figure 2A. After comparing the different systems, we note that the efficiency trend follows the following order: CoumC3 $>>$ CoumC2 $>$ CoumC1 $>$ CoumC9 >> CoumC4 >> CoumC5 $\sim$ CoumC6 $>$ CoumC12 $>$ CoumC7. This is directly related to their absorption properties but also to their reactivity (directly linked to their electron transfer quantum yields $\left(\phi_{\mathrm{et}}\right)$ and their free energy changes $\left(\Delta \mathrm{G}_{\mathrm{et}}\right)$ with iodonium salt - see below). 
These derivatives were also tested for thick samples $(1.4 \mathrm{~mm})$ under air and also while using the LED@ $405 \mathrm{~nm}$ as the source of irradiation. Good photopolymerization profiles are obtained in the presence of CoumC2, CoumC7 or CoumC12 when combined with Iod following the same order in term of efficiency compared to the FRP of thin films (CoumC2 > CoumC12 >> CoumC7; curves 2, 12 and 7 in Figure 3A and Table 2). Less favorable rates are obtained in this case, attributable to the inhibition due to oxygen which is generally noticed during FRP when realized under air, which reduces the overall performance of the photoinitiating system. In this case, the production of initiation radicals is considerably reduced, rendering the photoinitiating system unable to get over the oxygen inhibition.

Otherwise, coumarin derivatives were examined as Type II photoinitiators associated with an amine (NPG) leading to very efficient for a photo-reduction process for FRP thin samples (Figure 3B). High polymerization rates (Rp) and good acrylate function conversions (FC) were attained using these derivatives (Figure 3B; Table 2). Using LED @ $405 \mathrm{~nm}$, the efficiency trend for the FRP thins films follows the order: CoumC13 $>$ CoumC3 $>$ CoumC2 $>$ CoumC1 $>$ CoumC4 >> CoumC11. Again, both the photoreactivity and also the absorption properties are responsible for the efficiency of the system.

Furthermore, CoumC13/NPG presents high photoinitiating ability compared to the other derivatives among its series (curve 13 in Figure 3B; Table 2). It is quite obvious that CoumC13 can overcome the oxygen inhibition classically detected for FRP processes done under air. Conversely, CoumC2, CoumC3 or CoumC11 do not have the ability to do so. The better efficiency observed with CoumC13 can be attributed to its low absorbance @ $405 \mathrm{~nm}$ (absorbance evaluated in Table S1) which is in agreement with better light penetration during the photopolymerization. 
For the photo-reduction process, another amine was used (EDB). Only CoumC13 showed interesting polymerization profiles during the FRP of thin and thick TMPTA samples when irradiated at $405 \mathrm{~nm}$ with a LED (Figure S9A: curve 1 with $\mathrm{FC}=39 \%$ for thin film and curve 2 with FC $=69 \%$ for thick sample, respectively) in agreement with favorable electron transfer quantum yield (see below). No efficiency was shown when using the other derivatives in the presence of $\mathrm{EDB}$, demonstrating the production of radicals is not efficient enough to initiate the photopolymerization processes and to overcome the oxygen inhibition. Thus, such compounds are poor photoinitiators for a photo-reduction process using EDB as an additive. It should be noted that the absence of a decarboxylation step in the presence of EDB, may also be a reason for the better reactivity in the presence of Coum/NPG systems. The concerned step prevents any back electron transfer reaction (see the chemical mechanisms part below).

With regards to the three-component photoinitiating systems (PISs), huge performances have been noticed when NPG is added to the Coum/Iod systems where the maximum acrylate function conversions $(\mathrm{FC})$ and the polymerization rates $(\mathrm{Rp})$ reached in these cases are very much higher compared to that obtained with the two-component PISs e.g. FC $=59 \%$ for CoumC1/NPG/Iod $(0.2 \% / 1 \% / 1 \%$ w/w) compared to $41 \%$ for CoumC1/Iod $(0.2 \% / 1 \%$ w/w) (curve 1 in Figure 2C vs. Figure 2A, respectively; see also Table 2). Again, a better performance is also noted for the other coumarin derivatives showing the role of an amine (NPG) in increasing the conversion of the acrylate double bonds when it is added as a third component (Figure 2C vs. Figure 2A; Table 2). While comparing with the two-component Iod/NPG (1\%/1\% w/w) system, a very low polymerization ability is shown (curve 14 in Figure 2C), showing the huge role of coumarins. 
Besides, a comparable behavior was detected during the FRP of thick samples in the presence of the three-component (Coum/Iod/NPG) PISs where a raise of the FC and the Rp is noticed (see Figure 3 and Table 2).
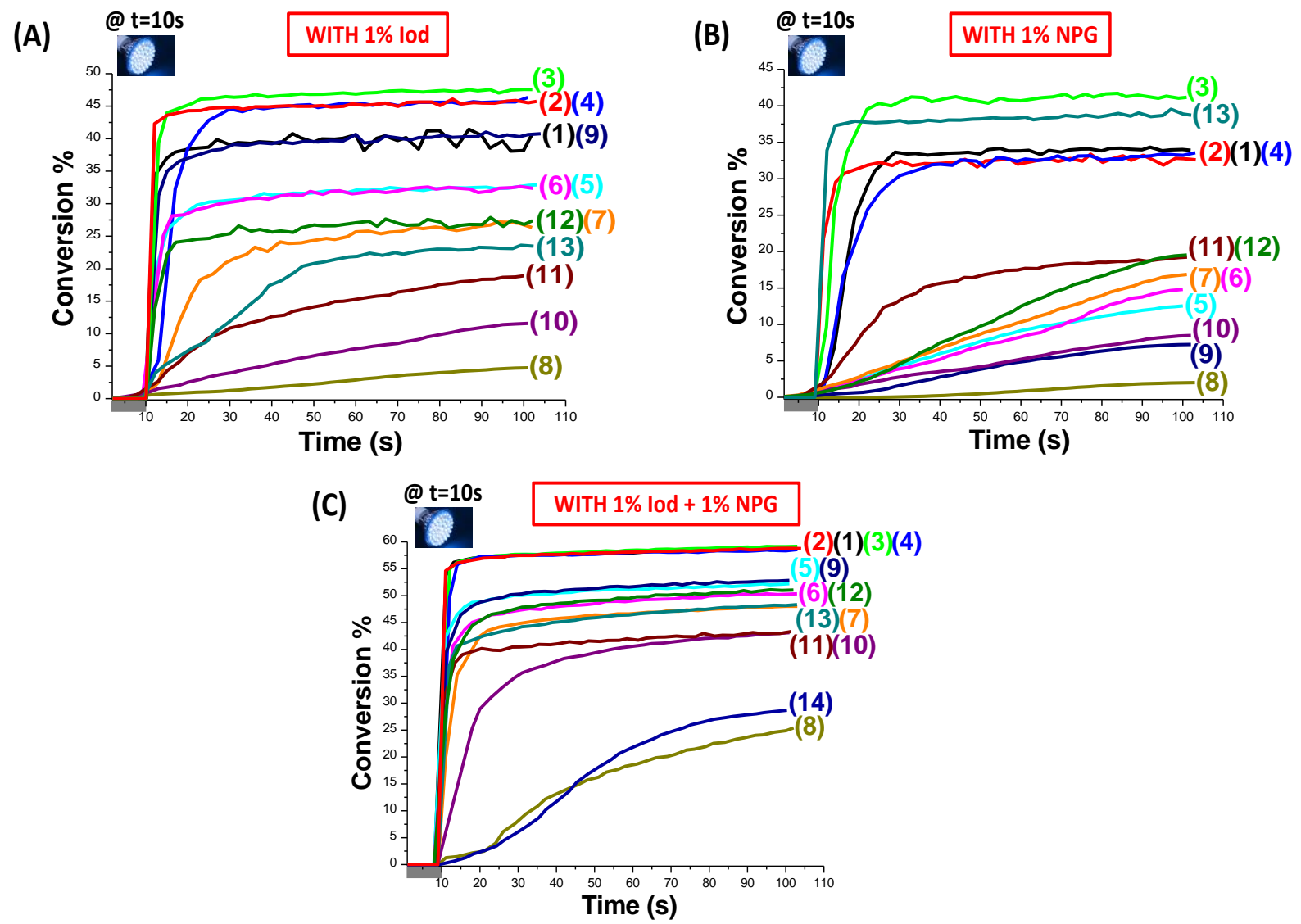

Figure 2. Polymerization profiles of TMPTA in laminate conditions (thin films; thickness = 25 $\mu \mathrm{m}$, LED@405 nm), with different two and three-component photoinitiating systems based on coumarin compounds: (A) PI/Iod (0.2\%/1\% w/w): (1) CoumC1/Iod; (2) CoumC2/Iod; (3) CoumC3/Iod; (4) CoumC4/Iod; (5) CoumC5/Iod; (6) CoumC6/Iod; (7) CoumC7/Iod; (8) CoumC8/Iod; (9) CoumC9/Iod; (10) CoumC10/Iod; (11) CoumC11/Iod; (12) CoumC12/Iod and (13) CoumC13/Iod. (B): PI/NPG (0.2\%/1\% w/w): (1) CoumC1/NPG; (2) CoumC2/NPG; (3) CoumC3/NPG; (4) CoumC4/NPG; (5) CoumC5/NPG; (6) CoumC6/NPG; (7) CoumC7/NPG; (8) CoumC8/NPG; (9) CoumC9/NPG; (10) CoumC10/NPG; (11) CoumC11/NPG; (12) CoumC12/NPG and (13) CoumC13/NPG. (C) PI/Iod/NPG (0.2\%/1\%/1\% w/w): (1) CoumC1/Iod/NPG; (2) CoumC2/Iod/NPG; (3) CoumC3/Iod/NPG; (4) CoumC4/Iod/NPG; (5) CoumC5/Iod/NPG; (6) CoumC6/Iod/NPG; (7) CoumC7/Iod/NPG; (8) CoumC8/Iod/NPG; (9) CoumC9/Iod/NPG; (10) CoumC10/Iod/NPG; (11) CoumC11/Iod/NPG; (12) CoumC12/Iod/NPG; (13) CoumC13/Iod/NPG and (14): Iod/NPG (1\%/1\% w/w). The irradiation is launched at $\mathrm{t}=10 \mathrm{~s}$. 

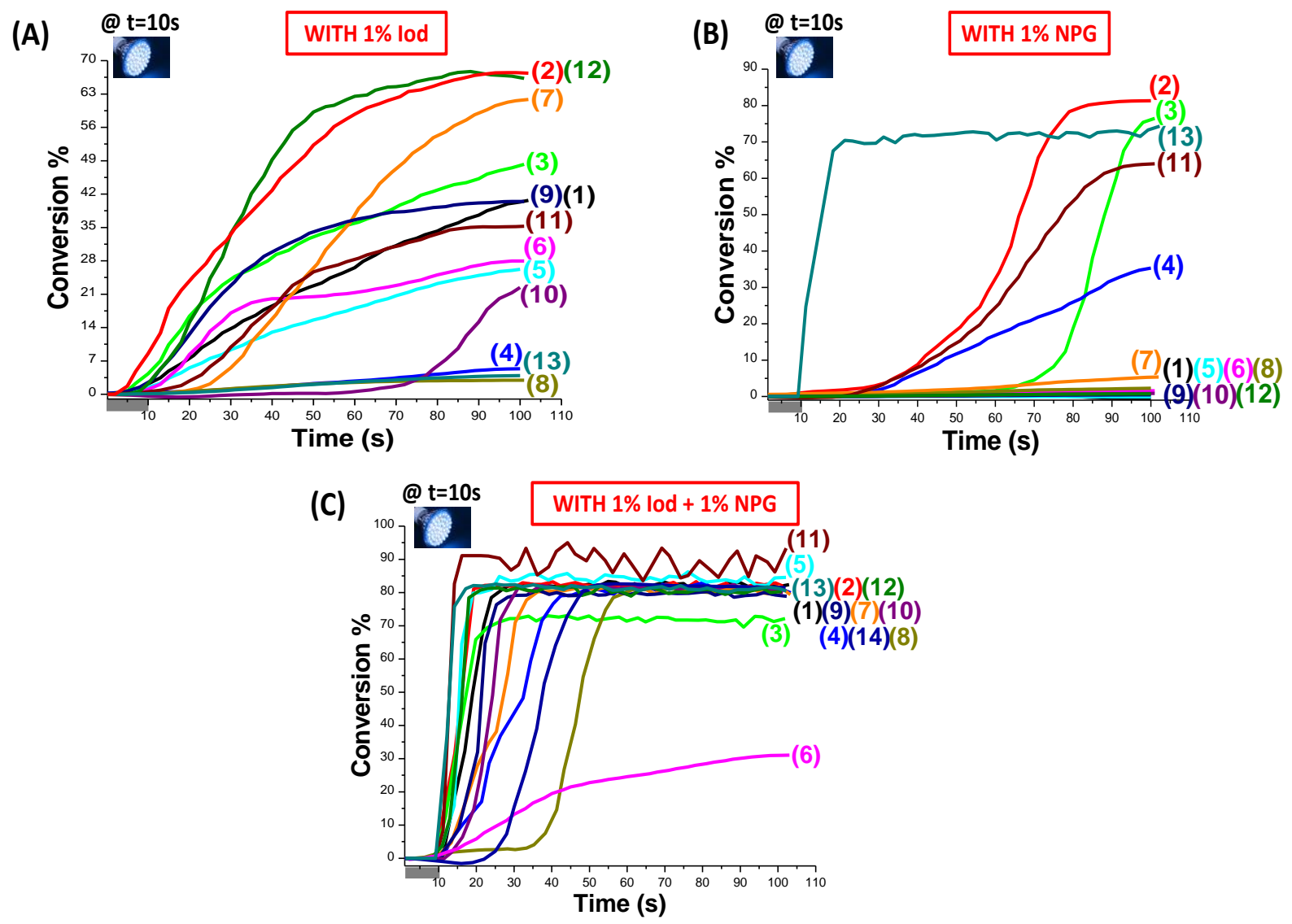

Figure 3. Polymerization profiles of TMPTA under air (thick samples; thickness $=1.4 \mathrm{~mm}$, LED emitting at $405 \mathrm{~nm}$ ) with different two and three-component photoinitiating systems based on coumarin compounds: (A) PI/Iod (0.2\%/1\% w/w): (1) CoumC1/Iod; (2) CoumC2/Iod; (3) CoumC3/Iod; (4) CoumC4/Iod; (5) CoumC5/Iod; (6) CoumC6/Iod; (7) CoumC7/Iod; (8) CoumC8/Iod; (9) CoumC9/Iod; (10) CoumC10/Iod; (11) CoumC11/Iod; (12) CoumC12/Iod and (13) CoumC13/Iod. (B): PI/NPG (0.2\%/1\% w/w): (1) CoumC1/NPG; (2) CoumC2/NPG; (3) CoumC3/NPG; (4) CoumC4/NPG; (5) CoumC5/NPG; (6) CoumC6/NPG; (7) CoumC7/NPG; (8) CoumC8/NPG; (9) CoumC9/NPG; (10) CoumC10/NPG; (11) CoumC11/NPG; (12) CoumC12/NPG and (13) CoumC13/NPG. (C) PI/Iod/NPG (0.2\%/1\%/1\% w/w): (1) CoumC1/Iod/NPG; (2) CoumC2/Iod/NPG; (3) CoumC3/Iod/NPG; (4) CoumC4/Iod/NPG; (5) CoumC5/Iod/NPG; (6) CoumC6/Iod/NPG; (7) CoumC7/Iod/NPG; (8) CoumC8/Iod/NPG; (9) CoumC9/Iod/NPG; (10) CoumC10/Iod/NPG; (11) CoumC11/Iod/NPG; (12) CoumC12/Iod/NPG; (13) CoumC13/Iod/NPG and (14): Iod/NPG (1\%/1\% w/w). The irradiation is launched at $\mathrm{t}=10 \mathrm{~s}$. 
Table 2. Final Acrylate Monomer Conversion (FC) for TMPTA after 100s (LED emitting at 405 $\mathrm{nm})$.

\begin{tabular}{|c|c|c|c|c|c|c|}
\hline & \multicolumn{3}{|c|}{ TMPTA, Thin sample $(25 \mu \mathrm{m})$ in laminate } & \multicolumn{3}{|c|}{ TMPTA, Thick sample $(1.4 \mathrm{~mm})$ under air } \\
\hline & Two-comp & $(0.2 \% / 1 \%$ & $\begin{array}{c}\text { Three- } \\
\text { component } \\
\text { PIS } \\
(0.2 \% / 1 \% / 1 \% \\
w / w)\end{array}$ & Two-comp & $(0.2 \% / 1 \%$ & $\begin{array}{c}\text { Three- } \\
\text { component } \\
\text { PIS } \\
(0.2 \% / 1 \% / 1 \% \\
w / w)\end{array}$ \\
\hline & +lod & +NPG & $+\operatorname{lod} /$ NPG & +lod & +NPG & $+\operatorname{lod} /$ NPG \\
\hline CoumC1 & $41 \%$ & $34 \%$ & $59 \%$ & $41 \%$ & n.p. & $83 \%$ \\
\hline CoumC2 & $46 \%$ & $33 \%$ & $59 \%$ & $68 \%$ & $82 \%$ & $83 \%$ \\
\hline CoumC3 & $48 \%$ & $42 \%$ & $59 \%$ & $49 \%$ & $77 \%$ & $73 \%$ \\
\hline CoumC4 & $46 \%$ & $34 \%$ & $59 \%$ & n.p. & $35 \%$ & $82 \%$ \\
\hline CoumC5 & $33 \%$ & n.p. & $53 \%$ & $26 \%$ & n.p. & $85 \%$ \\
\hline CoumC6 & $33 \%$ & n.p. & $51 \%$ & $28 \%$ & n.p. & $31 \%$ \\
\hline CoumC7 & $27 \%$ & n.p. & $49 \%$ & $62 \%$ & n.p. & $82 \%$ \\
\hline CoumC8 & n.p. & n.p. & $26 \%$ & n.p. & n.p. & $81 \%$ \\
\hline CoumC9 & $41 \%$ & n.p. & $53 \%$ & $41 \%$ & n.p. & $83 \%$ \\
\hline CoumC10 & n.p. & n.p. & $44 \%$ & n.p. & n.p. & $82 \%$ \\
\hline CoumC11 & $19 \%$ & $20 \%$ & $44 \%$ & $36 \%$ & $64 \%$ & $94 \%$ \\
\hline CoumC12 & $28 \%$ & $20 \%$ & $51 \%$ & $67 \%$ & n.p. & $82 \%$ \\
\hline CoumC13 & $24 \%$ & $39 \%$ & $49 \%$ & n.p. & $75 \%$ & $83 \%$ \\
\hline
\end{tabular}

\subsection{Free radical photopolymerization of methacrylates (BisGMA/TEGDMA)}

In this section, BisGMA/TEGDMA (70\%/30\% w/w) was used as a commercially available methacrylate monomer blend for the FRP of thick samples $(1.4 \mathrm{~mm})$ which is realized under air and in the presence of different two (Coum/Iod (or NPG or EDB) $(0.2 \% / 1 \%$ w/w)) and threecomponent (Coum/Iod/NPG $(0.2 \% / 1 \% / 1 \%$ w/w)) photoinitiating systems using coumarin derivatives as photoinitiators/photosensitizers (Figure S10). Coumarin derivatives, Iod, NPG or 
EDB alone show no efficiency for the FRP of TMPTA at $405 \mathrm{~nm}$, evidencing the crucial role of these derivatives in the overall performance of the photoinitiating system.

Interestingly, it is well obvious from the photopolymerization data that CoumC13 leads to the highest polymerization rate and the highest methacrylate function conversion when comparing the Coum/Iod systems to each other as shown in Figure S10A (thick samples). Taking into account the efficiency trend, it follows the following order: CoumC13 $>$ CoumC11 > CoumC2 >> CoumC3 > CoumC1. Remarkably, this behavior is inversely proportional to the absorbance of these compounds @ 405 nm which follows the opposite trend: CoumC1 >> CoumC3 >> CoumC2 >> CoumC11 >> CoumC13. This latter behavior is reasonable because at lowest absorbance, it allows more penetration of light in the depth making the photopolymerization process more favorable and resulting in higher conversion of the acrylate double bonds. The absorbance values are calculated according to Beer-Lambert law and the results are gathered in Table S1.

On the other hand, good polymerization profiles are also obtained for the Coum/NPG systems as evinced in Figure S10B. Here, the efficiency trend follows the order: CoumC13 >> CoumC11 > CoumC10 > CoumC4 > CoumC7 > CoumC2 > CoumC8. Different parameters are responsible for this behavior: the absorption properties of these compounds and their reactivity with the co-initiator to generate initiating radicals. In presence of EDB, only CoumC13 could initiate the FRP of thick samples (Figure S9B: FC $=67 \%$ for CoumC13/EDB).

Again, the great performance of the examined coumarin derivatives is noticed for methacrylate polymerization in thick samples when using three-component photoinitiating systems which are able to get over the oxygen inhibition evidenced with the two-component (Coum/Iod) PISs. It turns out that there is a big increase in FC and Rp after the addition of the amine as a third component (Figure S10C, Table 3). 
Table 3. Final Monomer Conversion (FC) for a BisGMA/TEGDMA (70\%/30\% w/w) blend after $150 \mathrm{~s}$ of irradiation at $405 \mathrm{~nm}$ using Different Photoinitiating Systems (under air; thickness $=1.4$ $\mathrm{mm})$.

\begin{tabular}{|c|c|c|c|}
\cline { 2 - 4 } & \multicolumn{2}{|c|}{ Two-component PIS (0.2\%/1\% w/w) } & $\begin{array}{c}\text { Three-component PIS } \\
\text { (0.2\%/1\%/1\% w/w) }\end{array}$ \\
\cline { 2 - 4 } & +lod & +NPG & +lod/NPG \\
\hline CoumC1 & $49 \%$ & $46 \%$ & $75 \%$ \\
\hline CoumC2 & $70 \%$ & $39 \%$ & $81 \%$ \\
\hline CoumC3 & $64 \%$ & $65 \%$ & $77 \%$ \\
\hline CoumC4 & $47 \%$ & n.p. & $78 \%$ \\
\hline CoumC5 & $27 \%$ & n.p. & $71 \%$ \\
\hline CoumC6 & $36 \%$ & $54 \%$ & $55 \%$ \\
\hline CoumC7 & $48 \%$ & $45 \%$ & $74 \%$ \\
\hline CoumC8 & n.p. & n.p. & $71 \%$ \\
\hline CoumC9 & $44 \%$ & $63 \%$ & $67 \%$ \\
\hline CoumC10 & n.p. & $56 \%$ & $77 \%$ \\
\hline CoumC11 & $75 \%$ & n.p. & $78 \%$ \\
\hline CoumC12 & $33 \%$ & $70 \%$ & $74 \%$ \\
\hline CoumC13 & $75 \%$ & & $80 \%$ \\
\hline & & & \\
\hline
\end{tabular}

\subsection{D Patterns using Coum/Iod, Coum/NPG or Coum/Iod/NPG Systems}

The very high photoreactivity noticed for the coumarins during the FRP of (meth)acrylates allows their use for 3D printing experiments. These tests were carried out under air using a laser diode at $405 \mathrm{~nm}$ using different two (Coum/Iod or NPG) or three-component (Coum/Iod/NPG) photoinitiating systems. Very thick 3D patterns were obtained, evidencing a remarkable spatial resolution $(50 \mu \mathrm{m})$ and requiring short writing time $(\sim 1 \mathrm{~min})$ when using this technique. 3D patterns were analyzed by numerical optical microscopy and the results are depicted in the Figure 4 and the Figure S11. 


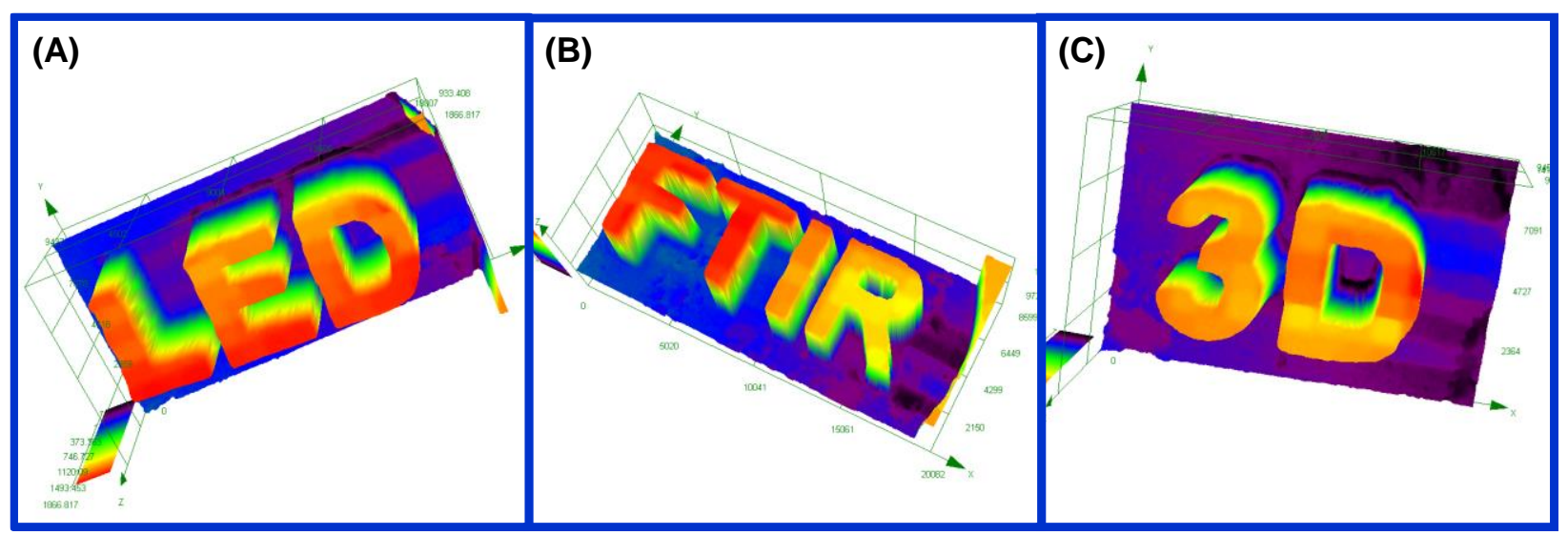

Figure 4. Free radical photopolymerization experiments for 3D printing technology using laser diode emitting at $405 \mathrm{~nm}$ : Photos of the 3D patterns obtained after characterization by numerical optical microscopy; (A) CoumC4/Iod/NPG $(0.06 \% / 0.3 \% / 0.3 \% \mathrm{w} / \mathrm{w})$ in TMPTA (thickness = $1840 \mu \mathrm{m})$; (B) CoumC7/Iod/NPG $(0.06 \% / 0.3 \% / 0.3 \% \mathrm{w} / \mathrm{w})$ in TMPTA (thickness $=3083 \mu \mathrm{m})$ and $(\mathbf{C})$ ComC9/Iod/NPG $(0.03 \% / 0.16 \% / 0.16 \% \mathrm{w} / \mathrm{w})$ in TMPTA (thickness $=1800 \mu \mathrm{m})$; respectively.

\subsection{Photocomposites Preparation Using Near-UV Conveyor Experiments}

Owing to the interesting and improved mechanical properties that characterize photocomposite materials starting from their high strength to their light weight and their chemical and corrosion resistance, photocomposites have become dominant emerging materials in many fields [32-36].

In this study, photocomposites were obtained by impregnation of the glass fibers by an organic resin and exposure to a LED emitting at $395 \mathrm{~nm}$. Photocomposites were typically prepared with $50 \%$ glass fibers $/ 50 \%$ resin w/w and photocomposites were polymerized at a belt speed of 2m/min. TMPTA or BisGMA/TEGDMA $(70 \% / 30 \% \mathrm{w} / \mathrm{w})$ were selected as the organic resins used for this study. High polymerization rates were observed using these derivatives, showing that such compounds are very efficient to fully cure composites even in low light penetration conditions. The photos of the initial and final composites are shown in Figure 5 and Figure S12. Note that the tack-free surface could be obtained. Similarly, very few passes were necessary to polymerize the 
bottom of the sample (one layer of glass fibers; thickness $=2 \mathrm{~mm}$ ) (see in Table S2 for TMPTA and Table S3 for BisGMA/TEGDMA). Interestingly, the synthesized composites remain light colored after irradiation.

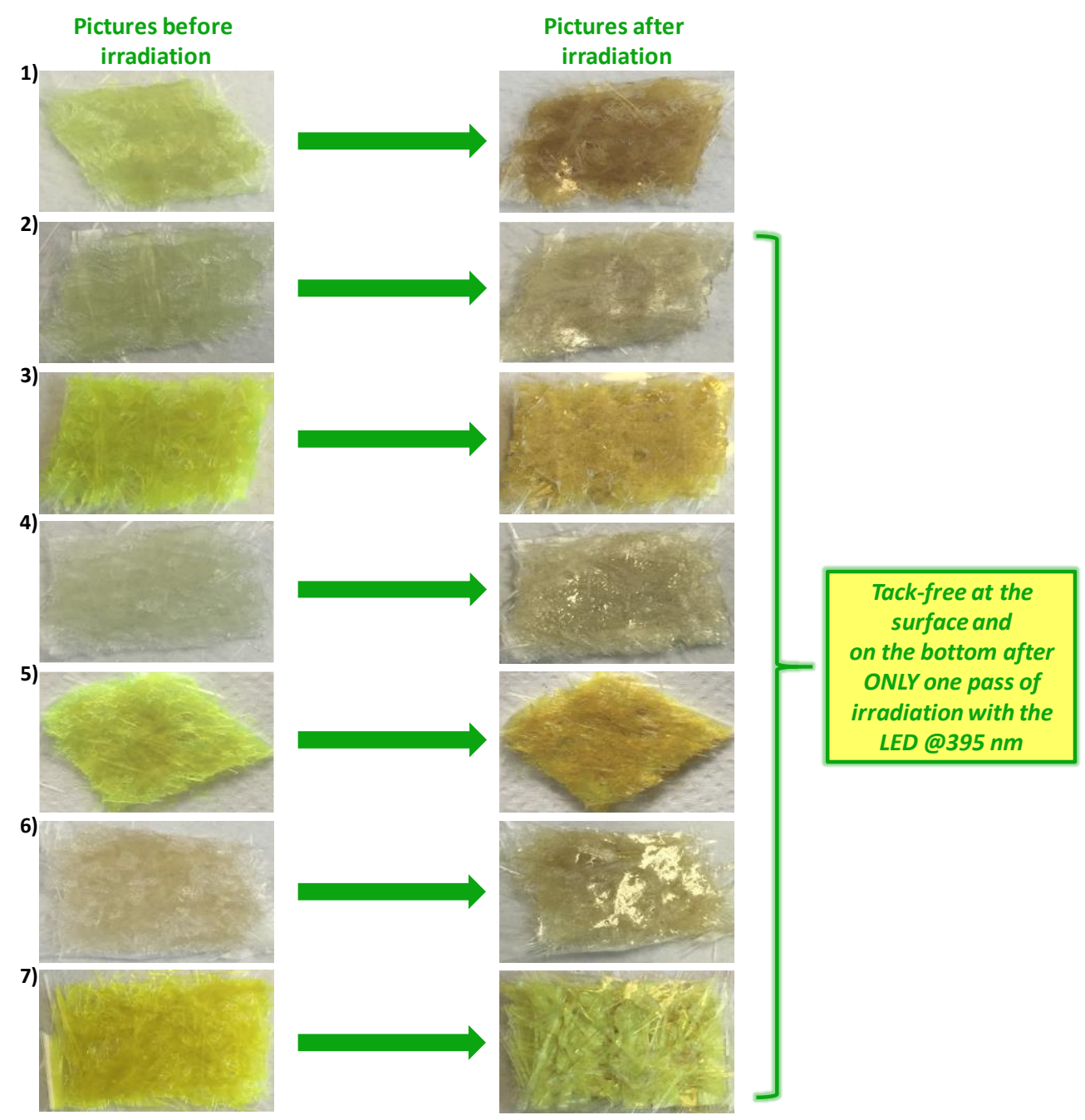

Figure 5. Photocomposites produced upon Near-UV light (LED @ $395 \mathrm{~nm}$ ) for different initiating systems in TMPTA: (1) $0.2 \%$ CoumC2 + 1\% Iod; (2) $0.2 \%$ CoumC4 + 1\% Iod + 1\% NPG; (3) $0.2 \%$ CoumC5 + 1\% Iod + 1\% NPG; (4) $0.2 \%$ CoumC7 + 1\% Iod + 1\% NPG; (5) $0.2 \%$ CoumC9 $+1 \%$ Iod $+1 \%$ NPG; (6) $0.2 \%$ CoumC10 + 1\% Iod + 1\% NPG and (7) $0.2 \%$ CoumC12 + $1 \%$ Iod $+1 \%$ NPG, respectively.

\subsection{Photochemical Mechanisms}

\subsubsection{Steady State Photolysis Studies}


A very fast photolysis was observed for CoumC3 in the presence of the iodonium salt when irradiated at $375 \mathrm{~nm}$ whereas a slower photolysis process was observed for CoumC3 alone (CoumC3/Iod in Figure S13B vs. CoumC3 in Figure S13A), indicating a strong CoumC3/Iod interaction. A similar behavior was noticed for the other coumarins (except for CoumC13/Iod where no photolysis occurs). Due to this latter interaction, a new photoproduct characterized by a significant absorption between 300 and $360 \mathrm{~nm}$ could be detected. Moreover, a clear consumption of CoumC3 is shown with Iod (curve 2 in Figure S13C) compared to CoumC3 alone (curve 1 in Figure S13C) by measuring the optical density at different irradiation time.

\subsubsection{Excited State Reactivity}

The study of the fluorescence quenching experiments for CoumC3 has been performed in acetonitrile and the obtained experimental results are given in Figure S14. First, the value of the first singlet excited state energy $\left(E_{S 1}\right)$ for the different investigated compounds is determined by the crossing point between the absorption and the fluorescence spectra e.g. $\mathrm{E}_{\mathrm{S} 1}=2.7 \mathrm{eV}$ for CoumC3 (see Table 4).

Table 4. Photophysical properties of the ${ }^{1,3}$ Coumarin/Iod and ${ }^{1,3}$ Coumarin/NPG systems in Acetonitrile.

\begin{tabular}{|c|c|c|c|c|c|c|c|c|c|}
\hline PI & $\begin{array}{c}E_{s 1} \\
(e V)\end{array}$ & $\begin{array}{c}\mathrm{E}_{\mathrm{T} 1} \\
(\mathrm{eV})^{\mathrm{a}}\end{array}$ & $\begin{array}{l}E_{o x} \\
(e V)\end{array}$ & $\begin{array}{c}\Delta \mathbf{G}_{\mathrm{et}(\mathrm{S} 1)}{ }^{\mathrm{b}} \\
\mathbf{1}^{(\mathrm{PI} / \mathrm{lod})} \\
(\mathrm{eV})\end{array}$ & $\begin{array}{c}\Delta \mathbf{G}_{\mathrm{et}(\mathrm{T} 1)}{ }^{\mathrm{b}} \\
{ }^{3}{ }^{(\mathrm{PI} / \mathrm{lod})} \\
(\mathrm{eV})\end{array}$ & $\begin{array}{c}\mathrm{K}_{\mathrm{SV}} \\
(\mathrm{PI} / \mathrm{lod}) \\
\left(\mathrm{M}^{-1}\right)\end{array}$ & $\begin{array}{l}\phi_{\text {et(S1) }}{ }^{\mathrm{C}} \\
(\mathrm{Pl} / \text { lod) }\end{array}$ & $\begin{array}{c}K_{S V} \\
(P I / N P G) \\
\left(M^{-1}\right)\end{array}$ & $\begin{array}{l}\phi_{\text {et(S1) }}{ }^{\mathrm{c}} \\
(\mathrm{PI} / \mathrm{NPG})\end{array}$ \\
\hline CoumC1 & 2.74 & 1.99 & 0.95 & -1.59 & -0.84 & 103.11 & 0.66 & 37.74 & 0.71 \\
\hline CoumC2 & 2.73 & 1.99 & 1.08 & -1.45 & -0.71 & 104.66 & 0.66 & 40.88 & 0.73 \\
\hline CoumC3 & 2.7 & 1.94 & 1.03 & -1.47 & -0.71 & 81.24 & 0.6 & 44.04 & 0.74 \\
\hline
\end{tabular}




\begin{tabular}{|l|c|c|c|c|c|c|c|c|c|}
\hline CoumC4 & 2.97 & 1.91 & 0.47 & -2.3 & -1.24 & 31.18 & 0.37 & 66.58 & 0.81 \\
\hline CoumC5 & 2.61 & 1.77 & 1.14 & -1.27 & -0.43 & 89.4 & 0.62 & 40.54 & 0.73 \\
\hline CoumC6 & 2.55 & 1.67 & 0.45 & -1.9 & -1.02 & 73.73 & 0.58 & 39.8 & 0.72 \\
\hline CoumC7 & 3.03 & 1.84 & 0.38 & -2.45 & -1.26 & 46.64 & 0.46 & 132.9 & 0.9 \\
\hline CoumC8 & 3.02 & 1.91 & 0.47 & -2.35 & -1.24 & 20.3 & 0.27 & 80.31 & 0.84 \\
\hline CoumC9 & 2.67 & 1.81 & 1.07 & -1.4 & -0.54 & 81.55 & 0.6 & 39.62 & 0.72 \\
\hline CoumC10 & 3.13 & 1.85 & 0.68 & -2.25 & -0.97 & 54.02 & 0.5 & 235.07 & 0.94 \\
\hline CoumC11 & 2.46 & 1.64 & 0.95 & -1.31 & -0.49 & 157.38 & 0.75 & 29.85 & 0.66 \\
\hline CoumC12 & 2.53 & 1.81 & 0.81 & -1.52 & -0.8 & 31.78 & 0.37 & 74.45 & 0.83 \\
\hline CoumC13 & 2.87 & 2.16 & 0.39 & -2.28 & -1.57 & 17.69 & 0.25 & 49.27 & 0.76 \\
\hline
\end{tabular}

a: triplet state energy level determined at DFT level.

b: for Iod, a reduction potential of $-0.2 \mathrm{eV}$ was used for the $\Delta \mathrm{G}_{\text {et }}$ calculations [37].

c: determined with the equation presented in [37].

High fluorescence quenching constants $\left(\mathrm{K}_{\mathrm{Sv}}\right.$; determined from fluorescence quenching experiments) were found for the coumarin/Iod (or NPG) systems, consistent with the highly favorable free energy changes $\left(\Delta \mathrm{G}_{\mathrm{et}}\right)$ for the associated electron transfer reaction $(\mathrm{r} 1, \mathrm{r} 2$ and $\mathrm{r} 1, \mathrm{r} 5$, r6 with Iod and NPG, respectively; Scheme 1; Table 4). Therefore, the high quantum yields of electron transfer were calculated ( $\phi_{\mathrm{et}}$; Table 4$)\left(\Delta \mathrm{G}_{\mathrm{et}}\right.$ is calculated according to eq. 1 and the quantum yields of electron transfer are calculated by applying equation (eq. 2)):

$$
\phi \mathrm{et}=K_{\mathrm{sv}}[\operatorname{Iod}] /\left(1+K_{\mathrm{sv}}[\operatorname{Iod}]\right)
$$

Free energy change for the electron transfer $\left(\Delta \mathrm{G}_{\mathrm{et}(\mathrm{T} 1)}\right)$ for ${ }^{3} \mathrm{Coum} / \mathrm{Iod}$ are found to be favorable $(<0)$, suggesting that the triplet state pathway can participate to some extend (Table 4$)$. 
It should be noted that the potentials of the first oxidation $\left(\mathrm{E}_{\mathrm{ox}}\right)$ peak of coumarins are obtained by cyclic voltammetry experiments.

Photochemical mechanism of the polymerization reaction is presented in Scheme 1 (reactions r1-r8) in agreement to those found for other dyes [20]. $\mathrm{r} 1$ and $\mathrm{r} 2$ are confirmed by Electron Spin Resonance technique (ESR) which allows the detection of the generated aryl radicals [37,38]. Indeed, radical adducts PBN/Ar ${ }^{\bullet}$ are clearly observed after irradiation of the Coum/Iod solution in the presence of PBN. Hyperfine coupling constants (hfcs): $\mathrm{a}_{\mathrm{N}}=14,1 \mathrm{G}$ and $\mathrm{a}_{\mathrm{H}}=2.1 \mathrm{G}$ which characterize the $\mathrm{PBN} / \mathrm{Ar}^{\bullet}$ radical adducts fully fit the data reported in the literature [39]. The participation of a NPG-Iod Charge Transfer Complex (CTC) cannot be ruled out (r3) as reported in [40]. This CTC structure allows the generation of aryl radicals $\mathrm{Ar}^{\bullet}(\mathrm{r} 4)$, consistent with the photoinitiating ability of NPG/Iod (curve 14 in Figures 2C, 3C and S10C).

For the photo-reduction process, a process of electron/proton transfer occurs between coumarins and NPG (Scheme 1) followed by a decarboxylation reaction proposed to avoid any back electron transfer reaction [37]. This latter reaction leads to the formation of $\mathrm{NPG}_{(-\mathrm{H} ;-\mathrm{CO} 2)}{ }^{\bullet}$ that can initiate the polymerization process for Coum/NPG systems. Finally, it is proposed that $\mathrm{r} 7$ and r8 can take place with the three-component systems as published in [40] for other investigated dye/iodonium salt/amine combinations. As a result, $\mathrm{Ar}^{\bullet}, \mathrm{NPG}_{(-\mathrm{H} ;-\mathrm{CO} 2)}^{\bullet}$ are respectively the polymerization initiating species generated through a pho-oxidation and a photo-reduction processes.

Scheme 1. Photochemical mechanisms proposed to support the FRP initiated by Coumarins. 


$$
\begin{aligned}
& \text { Coumarin } \rightarrow{ }^{*} \text { Coumarin } \quad(h v) \quad \text { (r1) } \\
& \text { "Coumarin }+\mathrm{Ar}_{2} \mathrm{I}^{+} \rightarrow \text { Coumarin }{ }^{\bullet+}+\mathrm{Ar}_{2} \mathrm{I}^{\bullet} \rightarrow \text { Coumarin }^{\bullet+}+\mathrm{Ar}^{\bullet}+\mathrm{ArI} \quad \text { (r2) } \\
& \mathrm{NPG}+\mathrm{Iod} \rightarrow[\mathrm{NPG}-\mathrm{Iod}]_{\mathrm{CTC}} \quad \text { (r3) } \\
& {[\mathrm{NPG}-\mathrm{Iod}]_{\mathrm{CTC}} \rightarrow \longrightarrow \rightarrow \mathrm{Ar}^{\bullet} \quad(\mathrm{hv})} \\
& { }^{*} \text { Coumarin }+\mathrm{NPG} \rightarrow(\text { Coumarin-H })^{\bullet}+\mathrm{NPG}_{(-\mathrm{H})}{ }^{\bullet} \quad(\mathrm{r} 5) \\
& \mathrm{NPG}_{(-\mathrm{H})}{ }^{\bullet} \rightarrow \mathrm{NPG}_{(-\mathrm{H} ;-\mathrm{CO} 2)}^{\bullet}+\mathrm{CO}_{2} \quad \text { (r6) } \\
& \mathrm{NPG}_{(-\mathrm{H} ;-\mathrm{CO} 2)^{\bullet}}+\mathrm{Ar}_{2} \mathrm{I}^{+} \rightarrow \mathrm{NPG}_{(-\mathrm{H} ;-\mathrm{CO} 2)^{+}}+\mathrm{Ar}^{\bullet}+\mathrm{ArI} \\
& (\text { Coumarin-H })^{\bullet}+\mathrm{Ar}_{2} \mathrm{I}^{+} \rightarrow \text { Coumarin }+\mathrm{H}^{+}+\mathrm{Ar}^{\bullet}+\mathrm{ArI}
\end{aligned}
$$

\section{Simulation of the Polymerization Profiles}

\subsection{Kinetic Equations}

The proposed photochemical mechanisms shown by Scheme 1 may be further summarized by the kinetic of Figure S15, using the simplified notations: coumarin derivatives=C, iodonium $=[\mathrm{A}]$, amine $=[\mathrm{B}] ; \mathrm{Ar}_{2} \mathbf{I}^{\bullet}=\mathrm{R}^{\prime}, \mathrm{Ar}^{\bullet}=\mathrm{R},(\mathrm{Coum}-\mathrm{H})^{\bullet}=\mathrm{S}$, and Amine $(-\mathrm{H}){ }^{\bullet}=\mathrm{S}^{\prime}$.

As shown by Figure S15, a three-component system, [C], [A] and [B] in the presence of oxygen is proposed. The ground state initiator, $\mathrm{C}$, is excited by a visible light to its triplet excited state, $\mathrm{T}^{*}$, by a quantum yield $(\mathrm{q}), \mathrm{T}^{*}$ further interacts with the initiator $[\mathrm{A}]$ and the co-initiator (enhancer) $[\mathrm{B}]$ producing radical $\left[\mathrm{R}^{\prime}, \mathrm{R}\right]$ and $\left[\mathrm{S}^{\prime}, \mathrm{S}\right]$, respectively. $\mathrm{S}$ could react with $[\mathrm{A}]$ to generate addition radical $\mathrm{R}$, whereas $\mathrm{S}$ ' could react with $[\mathrm{A}]$ to generate radical $\mathrm{R}$ and the regeneration of the initiator, for polymerization of the monomer $[\mathrm{M}]$, in the type-II (or oxygen-mediated) process, $\mathrm{T}^{*}$ also interacts with $\left[{ }^{3} \mathrm{O}_{2}\right]$ to generate a singlet oxygen $\left[{ }^{1} \mathrm{O}_{2}\right]$ which can then interact with $[\mathrm{A}]$ for polymerization or relaxed to $\left[\mathrm{O}_{2}\right]$, or crosslink with [M]. 
The kinetic equations for our previous system [41-44] are revised to include the enhancer, electron-donor molecule, [B], as the co-initiator for additional radical $\mathrm{R}$ produced from initiator [A]. The so-called quasi-steady state assumption $[13,14]$ was used to model the experimental results. Lifetimes of the triplet states of the PS, the radicals $(\mathrm{R}, \mathrm{S})$, and the singlet oxygen $\left({ }^{1} \mathrm{O}_{2}\right)$ are very short (ns to $\mu$ s time scale). As a result of this, they can decay or react with cellular matrix immediately after formation. Consequently, the following equations can be proposed: $\mathrm{dT}^{*} / \mathrm{dt}=\mathrm{dR}^{\prime} / \mathrm{dt}=\mathrm{dS} / \mathrm{dt}=\mathrm{dS} / \mathrm{dt}=\mathrm{d}^{1} \mathrm{O}_{2} / \mathrm{dt}=0$. Under these quasi-steady-state conditions, we obtain [43]

$\frac{\partial \mathrm{C}}{\partial \mathrm{t}}=-\mathrm{bIg}\left([\mathrm{A}]+[\mathrm{B}]+\operatorname{kgg}^{\prime} \mathrm{C}\left[\mathrm{O}_{2}\right]\right) \mathrm{C}+\mathrm{R}_{\mathrm{E}}$

$\frac{\partial[\mathrm{A}]}{\partial \mathrm{t}}=-\left(\mathrm{bICg}+\mathrm{k}^{\prime \prime} \mathrm{S}\right)[\mathrm{A}]$

$\frac{\partial[\mathrm{B}]}{\partial \mathrm{t}}=-\mathrm{bICg}[\mathrm{B}]$

$\frac{\partial \mathrm{R}}{\partial \mathrm{t}}=\left(\mathrm{bICg}+\mathrm{k} " \mathrm{~S}+\mathrm{k}^{\prime \prime} \mathrm{S}^{\prime}\right)[\mathrm{A}]-\mathrm{GR}-2 \mathrm{k}_{\mathrm{T}} \mathrm{R}^{2}$

$\frac{\partial \mathrm{S}}{\partial \mathrm{t}}=\mathrm{bICg}[\mathrm{B}]-\left(\mathrm{k}_{5}^{\prime}+\mathrm{k}^{\prime \prime}[\mathrm{A}]+\mathrm{k}_{12} \mathrm{R}\right) \mathrm{S}$

$\frac{\partial \mathrm{S}^{\prime \prime}}{\partial \mathrm{t}}=\mathrm{bICg}[\mathrm{B}]-\left(\mathrm{k}_{5}{ }+\mathrm{k}^{\prime \prime}[\mathrm{A}]+\mathrm{k}_{12}^{\prime} \mathrm{R}\right) \mathrm{S}^{\prime}$

$\frac{\partial\left[\mathrm{O}_{2}\right]}{\partial \mathrm{t}}=-\left(\mathrm{bICg}+\mathrm{k}_{9} \mathrm{R}\right)\left[\mathrm{O}_{2}\right]$

$\frac{\partial[\mathrm{M}]}{\partial \mathrm{t}}=-\left(\mathrm{bICgg}^{\prime}\left[\mathrm{O}_{2}\right]+\mathrm{k}^{\prime} \mathrm{R}\right)[\mathrm{M}]$

$\mathrm{G}=\mathrm{k}_{5}+\mathrm{k}^{\prime}[\mathrm{M}]+\mathrm{k}_{9}\left[\mathrm{O}_{2}\right]+\mathrm{k}_{12} \mathrm{~S}+\mathrm{k}_{12}^{\prime} \mathrm{S}^{\prime}$

where $\mathrm{g}=\mathrm{k}_{8} /\left(\mathrm{k}_{5}+\mathrm{k}_{3}\left[\mathrm{O}_{2}\right]+\mathrm{k}_{4}[\mathrm{~A}]+\mathrm{k}_{7}[\mathrm{~B}]\right), \mathrm{g}^{\prime}=\mathrm{k}_{3} /\left(\mathrm{k}_{6}+\mathrm{k}^{\prime}[\mathrm{M}]+\mathrm{k}_{11} \mathrm{C}\right) ; \mathrm{k}^{\prime}=\left(\mathrm{k}_{11} / \mathrm{k}_{8}\right) ;$ the initiator-C 
regeneration term $\mathrm{R}_{\mathrm{E}}=\mathrm{k}_{5} \mathrm{RS}{ }^{\prime}+\mathrm{k}_{9} \mathrm{R}\left[\mathrm{O}_{2}\right]+2 \mathrm{k}_{\mathrm{T}} \mathrm{R}^{\prime 2}$. In deriving above equations, we have used the steady-state $\mathrm{T}^{*}=\mathrm{bIgC}, \mathrm{k}_{8}\left[{ }^{1} \mathrm{O}_{2}\right]=\mathrm{k}_{3}\left[{ }^{3} \mathrm{O}_{2}\right] \mathrm{Tg}^{\prime}=\mathrm{gg}^{\prime}\left[\mathrm{O}_{2}\right]$.

The dynamic light intensity is given by [41]

$\frac{\partial \mathrm{I}(\mathrm{z}, \mathrm{t})}{\partial \mathrm{z}}=-\mathrm{A}^{\prime}(\mathrm{z}, \mathrm{t}) \mathrm{I}(\mathrm{z}, \mathrm{t})$

$\mathrm{A}^{\prime}(\mathrm{z}, \mathrm{t})=2.3\left[\left(\mathrm{a}^{\prime}-\mathrm{b}^{\prime}\right) \mathrm{C}(\mathrm{z}, \mathrm{t})+\mathrm{b}^{\prime} \mathrm{C}_{0} \mathrm{~F}^{\prime}+\mathrm{Q}^{\prime}\right]$

a' and b' corresponds to the molar extinction coefficients of initiator-C and the photolysis product, respectively; Q' is the absorption coefficient of the monomer. Where $b=83.6 \mathrm{a}$ 'wq, with w being the light wavelength (in $\mathrm{cm}$ ) and $\mathrm{q}$ is the triplet state $[\mathrm{T}]$ quantum yield, a' in $(1 / \mathrm{mM} / \%)$ and $\mathrm{I}(\mathrm{z}, \mathrm{t})$ in $\mathrm{mW} / \mathrm{cm}^{2}$. All the reaction rate constants are defined by the associated coupling terms. More details can be found in Ref. [41].

Solving for the steady-state of Equations (eq. 7) and (eq. 8), $\mathrm{S}=\mathrm{S}$ ' $=$ bICgg", with g" $=\mathrm{k}_{4} /\left(\mathrm{k}_{5}+\right.$ $\left.+\mathrm{k}_{4}[\mathrm{~A}]+\mathrm{k}_{12} \mathrm{R}\right)$

and substituting to Equation (eq. 6), we obtain

$\frac{\partial \mathrm{R}}{\partial \mathrm{t}}=\mathrm{H}(\mathrm{t})-\mathrm{GR}-2 \mathrm{k}_{\mathrm{T}} \mathrm{R}^{2}$

$\mathrm{H}(\mathrm{t})=\operatorname{bICg}\left(1+2 \mathrm{~g}^{\prime \prime}[\mathrm{B}]\right)[\mathrm{A}]$

which has a steady-state given by,

$R=\left(\frac{1}{4 k_{\mathrm{T}}}\right)\left(-G+\sqrt{\mathrm{G}^{2}+8 \mathrm{k}_{\mathrm{T}} \mathrm{H}}\right)$

where $\mathrm{G}=\mathrm{k}_{5}+\mathrm{k}_{9}\left[\mathrm{O}_{2}\right]+\mathrm{k}^{\prime}[\mathrm{M}]+2 \mathrm{k}_{12} \mathrm{bICgg}$ '.

For $\mathrm{H} \gg \mathrm{G}^{2}$, we obtain an approximate radical given by 
$\mathrm{R}=\sqrt{0.5 \mathrm{H} / \mathrm{k}_{\mathrm{T}}}-(1-0.5 / \sqrt{\mathrm{H}}) \mathrm{G} /\left(4 \mathrm{k}_{\mathrm{T}}\right)$

(eq. 17)

\subsection{Conversion Efficacy}

Conversion efficiency of the monomer $[\mathrm{M}]$ is defined by $\mathrm{C}_{\mathrm{E}}=1-[\mathrm{M}] /[\mathrm{M}]_{0}=1-\exp (-\mathrm{S})$, where the $\mathrm{S}$ function is given by the time integral of the total rate function, $\mathrm{R}_{\mathrm{T}}$. Using the total rate function given by Equation (eq. 10), and Equation (eq. 17) for $\mathrm{R}$, and for $\mathrm{g}^{\prime} \mathrm{C}=\mathrm{k}_{3} / \mathrm{k}_{11}=\mathrm{k}_{31}$, for $\left(\mathrm{k}_{6}+\mathrm{k}^{\prime}[\mathrm{M}]\right)<<\mathrm{k}_{11} \mathrm{C}$, we obtain

$\frac{\partial[\mathrm{M}]}{\partial \mathrm{t}}=-\mathrm{R}_{\mathrm{T}}[\mathrm{M}]$

$\mathrm{R}_{\mathrm{T}}=\operatorname{bIgk}_{31}\left[\mathrm{O}_{2}\right]+\mathrm{K} \sqrt{\mathrm{H}}-\mathrm{k}^{\prime} \mathrm{G} /\left(4 \mathrm{k}_{\mathrm{T}}\right)$

where $\mathrm{K}=0.5 \mathrm{k}^{\prime} /\left(\mathrm{k}_{\mathrm{T}}\right)^{0.5}$, We note that $\mathrm{R}_{\mathrm{T}}$ consists of three parts: the type-II oxygen-mediated (first term), the free radical initiated (second term, $\mathrm{H}$ ), and the reduction $\mathrm{G}$ term; where the $\mathrm{H}$ function has two contributions given by Equation (eq. 15), $\mathrm{H}=(\mathrm{bICg})(1+2 \mathrm{~g}$ "[B] $)[\mathrm{A}]$, which is enhanced by the co-initiator $[\mathrm{B}]$.

Analytic solution of Equation (eq. 18) for the conversion efficacy is related to $\mathrm{S}$ by $\mathrm{C}_{\mathrm{EFF}}=1$ $\exp (-\mathrm{S})$, where the $\mathrm{S}$-function is given by the time integral of $\mathrm{R}_{\mathrm{T}}$. For a type-I dominated case with the first term of Equation (eq. 19) neglected, we obtained [42]:

$\mathrm{S}=\mathrm{K}\left(1+\mathrm{B}_{0} / \mathrm{A}_{0}\right) \mathrm{G}^{\prime}(\mathrm{z}, \mathrm{t}) \sqrt{0.5 \mathrm{bXI_{0 } \mathrm { C } _ { 0 }}}$

$\mathrm{G}^{\prime}(\mathrm{z}, \mathrm{t})=\left[1-\exp \left(-\mathrm{B}^{\prime \prime} \mathrm{t}\right)\right] / B^{\prime \prime}$

where $B "=0.5\left(B^{\prime}-A_{1}\right), X=\exp \left[-z A_{2}\right]$, with $A_{2}=1.15\left(a^{\prime}+b^{\prime}\right) C_{0}+2.3 Q$.

The steady-state of Equation (eq. 20) is given by, when $\mathrm{G}^{\prime}=1 / \mathrm{B}^{\prime \prime}$, or

$\mathrm{S}=\mathrm{K}\left(1+\mathrm{B}_{0} / \mathrm{A}_{0}\right) \sqrt{\left.\mathrm{C}_{0} /(8 \mathrm{bXI})_{0}\right)}$

(eq. 22) 
which shows that the enhanced efficacy is proportional to the concentration ratio of $\mathrm{B}_{0} / \mathrm{A}_{0}$, and governed by a scaling law of $\left[\mathrm{C}_{0} /\left(\mathrm{bXI}_{0}\right)\right]^{0.5}$.

\subsection{Numerical Analysis}

Greater details of numerical results of Equations (eq. 3) to (eq. 19) will be presented elsewhere. In the following, we will show two important factors influencing the function conversions (FC): the oxygen inhibition effect, and the co-initiator-B concentrations. Figure S16 shows the role of oxygen, in which FC is a decreasing function of oxygen concentration. Noticeably, a high oxygen concentration leads to a large inhibition effect which reduces the radical (R), as also evidenced by Equation (eq. 17) that $\mathrm{R}$ is a decreasing function of oxygen. A stronger oxygen inhibition effects can also take place in thinner thickness.

Figure S17 shows the crucial role of the co-initiator-B concentrations $\left(\mathrm{B}_{0}\right)$, in which higher $\mathrm{B}_{0}$ leads to higher FC, i.e. three-component system (with $\mathrm{B}_{0}>0$ ) is more efficient than 2-component (with $\mathrm{B}_{0}=0$ ). These results are also predicted by Equations (eq. 15) and (eq. 20), which show the enhanced effects due to the extra term $\mathrm{B}_{0} / \mathrm{A}_{0}$, in the 3-component system.

\subsection{Analysis of Measurements}

Our measured data demonstrated that the function conversion (FC) and the rate of polymerization (Rp) are governed by multiple factors. As shown by (eq. 15), the initiating factor (H) is governed by the parameter $\mathrm{b}=83.6 \mathrm{a}$ 'wq, which is proportional to the extinction coefficients of initiator-C (a').and the triplet state quantum yield (q). This feature is shown by Figure 2 that FC is an increasing function of compound absorption and their reactivity (electron transfer quantum yield). 
As shown by (eq. 19), the total rate function for the radical $\left(\mathrm{R}_{\mathrm{T}}\right)$ consists of three parts: the type-II oxygen-mediated (first term), the type-I radical $(\mathrm{R})$ initiated (second term, $\mathrm{H}$ ), and the reduction factor due to oxygen inhibition (the last term, G). Our measured data of Figure S10A shows the efficiency trend follows the order of CoumC2 $>$ CoumC12 $>$ CoumC7, in which the initiation radical yield is unable to overcome the oxygen inhibition in CoumC12 and CoumC7.

Our Figure S9A also shows that EDB having a low initiating radical yields (q) are not able to get over the oxygen inhibition. These features may be easily realized by when $\mathrm{H}$ is less that $\mathrm{G}$ in Equation (eq. 15). Similarly, as shown by Figure S10B and Table 2, CoumC13 can overcome the oxygen inhibition classically detected during the FRP under air while CoumC2, CoumC3 or CoumC11 do not have the ability to do so. Figure S10B also shows that better efficiency observed with CoumC13 can be attributed to its lowest absorbance with deepest penetration of light. This feature may be realized by Equation (eq. 20), in which the S function (and the FC) is a decreasing function of the polymer thickness (z).

Figure S10C demonstrated that the three-component systems are able to get over the oxygen inhibition detected with the two-component (Coum/Iod) PISs. In addition, a big increase of the FC and the polymerization rate (Rp) after the addition of the amine (NPG) as a third component is detectable. This feature may be realized by Equation (eq. 20) and Figure S16, in which a higher $\mathrm{B}_{0}$, or higher concentration of amine (NPG), leads to higher FC, i.e., 3-component system (with $\mathrm{B}_{0}>0$ ) is more efficient than 2-component (with $\mathrm{B}_{0}=0$ ).

Besides this single-wavelength, 3-component photopolymerization, we have recently developed two-wavelength and three-wavelength, 3-component system for 3D bioprinting [45, 46]. 


\section{Conclusion}

In this study, the FRP of (meth)acrylates using the new synthesized set of in-silico developed coumarin derivatives has been investigated through two distinct strategies: a photooxidation approach based on an iodonium salt and a photoreduction approach based on an amine under visible LED as source of irradiation. As a striking result of this in-silico design, different classes of coumarins can exhibit a high efficiency i.e. both their light absorption and excited state processes are well adapted to ensure a high photochemical reactivity. The good performances of coumarin derivatives paved the way for their use in 3D printing technology which allows the preparation of 3D thick samples using laser diode at $405 \mathrm{~nm}$. In addition, coumarins have found an interesting and worthwhile application for an industrial domain which concerns their use in thick glass fiber synthesis photocomposites. Remarkably, a kinetic model has been proposed to anticipate the polymerization profiles based on the determined chemical mechanisms. Development of new high-performance photoinitiating systems and novel co-initiators is currently under progress.

\section{ACKNOWLEDGMENTS}

The Lebanese group would like to thank "The Association of Specialization and Scientific Guidance" (Beirut, Lebanon) for funding and supporting this scientific work. JL thank the Region Grand-Est for the funding of the MIPPI-4D project. This work was granted access to the HPC resources of the Monocenter of the University of Strasbourg.

Supporting Information: Figure S1-S6: Synthetic routes to CoumC1-C13; Scheme S1: Structures of the commercial chemical compounds used in this study; Figure S7: Absorption spectra of the investigated coumarins in acetonitrile; Figure S8: Contour plots of HOMOs and 
LUMOs for the coumarin derivatives; structures optimized at the B3LYP/6-31G* level of theory; Table S1: Extinction coefficients and absorbances at the emission wavelength of the LED @ 405 $\mathrm{nm}$ (thickness = $1.4 \mathrm{~mm}$ ); Figure S9: Typical (meth)acrylate function conversion-time profiles for thin $(25 \mu \mathrm{m}$, in laminate) and/or thick (1.4 mm, under air) TMPTA (A) or BisGMA/TEGDMA (B) samples, in the presence of CoumC13/EDB couple upon irradiation with the LED at $405 \mathrm{~nm}$; Figure S10: Typical methacrylate function conversion-time profiles for thick (1.4 mm, under air) BisGMA/TEGDMA samples using different photoinitiating systems based on coumarins, upon irradiation with the LED at $405 \mathrm{~nm}$; Figure S11: 3D patterns characterized by a numerical optical microscopy; Figure S12: Synthesis of photocomposites (thickness $=2 \mathrm{~mm}$ ) using methacrylate resins upon Near-UV light (LED @395 nm); Table S2 and Table S3: Number of passes to be tack-free for impregnated glass fibers with (meth)acrylate resins using a Near-UV conveyor (LED @395 nm), belt speed used $=2 \mathrm{~m} \cdot \mathrm{min}^{-1}$; Figure S13: Photolysis and Photodegradation of CoumC3 without and with iodonium salt; Figure S14: Fluorescence quenching of CoumC3, and Stern-Volmer treatment; Figure S15: Schematics of photochemical pathways in a 3-component [C/B/A] system; Figure S16: The dynamical profiles for the functional conversion (A), and radical (B), for various oxygen initial concentration; and Figure S17: Conversion profiles for various initiator-B concentrations. 


\section{REFERENCES}

[1] Satpati A. K.; Kumbhakar M.; Nath S.; Pal H. Photophysical Properties of Coumarin-7 Dye:

Role of Twisted Intramolecular Charge Transfer State in High Polarity Protic Solvents. Photochem. Photobiol. 2009, 85, 119-129.

[2] Kielesiński Ł.; Gryko D. T.; Sobolewski A. L.; Morawski O. W. Effect of Conformational Flexibility on Photophysics of Bis-Coumarins. Phys. Chem. Chem. Phys. 2018, 20, 14491-14503.

[3] Ayyangar N. R.; Srinivasan K. V.; Daniel T. Polycyclic Compounds Part VII. Synthesis Laser Characteristics and Dyeing Behaviour of 7-Diethylamino-2H-1-Benzopyran-2-Ones. Dyes. Pigm. 1991, 16, 197-204.

[4] Liu X.; Cole J. M.; Waddell P. G.; Lin T.C.; Radia J.; Zeidler A. Molecular Origins of Optoelectronic Properties in Coumarin Dyes: Toward Designer Solar Cell and Laser Applications. J. Phys. Chem. A. 2012, 116, 727-737.

[5] Guo L.; Yang D.; Xia L.; Qu F.; Dou Y.; Qu F.; Kong R.; You J. A Highly Water-Soluble, Sensitive, Coumarin-Based Fluorescent Probe for Detecting Thiols, and Its Application in Bioimaging. New J. Chem. 2017, 41, 15277-15282.

[6] Li X.; Huo F.; Yue Y.; Zhang Y.; Yin C. A Coumarin-Based "off-on” Sensor for Fluorescence Selectivily Discriminating GSH from Cys/Hcy and Its Bioimaging in Living Cells. Sens. Actuators. B. Chem. 2017, 253, $42-49$.

[7] Lee M.T.; Yen C.K.; Yang W.P.; Chen H.H.; Liao C.H.; Tsai C.H.; Chen C.H. Efficient Green Coumarin Dopants for Organic Light-Emitting Devices. Org. Lett. 2004, 6, 1241-1244.

[8] Aguilar M. R.; Román J. S. Smart Polymers and Their Applications; Elsevier. 2014. 
[9] Wolff T.; Görner H. Photocleavage of Dimers of Coumarin and 6-Alkylcoumarins. J. Photochem. Photobiol. A. Chem. 2010, 209, 219-223.

[10] Zhao L.; Loy D. A.; Shea K. J. Photodeformable Spherical Hybrid Nanoparticles. J. Am. Chem. Soc. 2006, 128, 14250-14251.

[11] Jiang X.; Wang R.; Ren Y.; Yin J. Responsive Polymer Nanoparticles Formed by Poly(Ether Amine) Containing Coumarin Units and a Poly(Ethylene Oxide) Short Chain. Langmuir. 2009, 25, 9629-9632.

[12] Jiang J.; Shu Q.; Chen X.; Yang Y.; Yi C.; Song X.; Liu X.; Chen M. Photoinduced Morphology Switching of Polymer Nanoaggregates in Aqueous Solution. Langmuir. 2010, 26, $14247-14254$.

[13] Hamdi N.; Passarelli V.; Romerosa A. Synthesis, Spectroscopy and Electrochemistry of New 4-(4-Acetyl-5- Substituted-4, 5-Dihydro-1, 3,4-Oxodiazol-2-Y1)Methoxy)-2H-Chromen-2-Ones as a Novel Class of Potential Antibacterial and Antioxidant Derivatives. C. R. Chim. 2011, 14, 548-555.

[14] Harvey R. G.; Cortez C.; Ananthanarayan T. P.; Schmolka S. A New Coumarin Synthesis and Its Utilization for the Synthesis of Polycyclic Coumarin Compounds with Anticarcinogenic Properties. J. Org. Chem. 1988, 53, 3936-3943.

[15] Manolov I.; Maichle-Moessmer C.; Danchev N. Synthesis, Structure, Toxicological and Pharmacological Investigations of 4-Hydroxycoumarin Derivatives. Eur. J. Med. Chem. 2006, $41,882-890$. 
[16] Oh J. K.; Stöeva V.; Rademacher J.; Farwaha R.; Winnik M. A. Synthesis, Characterization, and Emulsion Polymerization of Polymerizable Coumarin Derivatives: Polymerizable Coumarin Derivatives. J. Polym. Sci. Part A: Pol. Chem. 2004, 42, 3479-3489.

[17] Tong U.; Chen W.; Ritchie C.; Wang X.; Song Y.F. Reversible Light-Driven Polymerization of Polyoxometalate Tethered with Coumarin Molecules. Chem. Eur. J. 2014, 20, 1500-1504.

[18] Li C.; Luo L.; Wang S.; Huang W.; Gong Q.; Yang Y.; Feng S. Two-Photon MicrostructurePolymerization Initiated by a Coumarin Derivative/Iodonium Salt System. Chem. Phys. Lett. 2001, $340,444-448$.

[19] Nazir R.; Danilevicius P.; Ciuciu A. I.; Chatzinikolaidou M.; Gray D.; Flamigni L.; Farsari M.; Gryko D. T. $\pi$-Expanded Ketocoumarins as Efficient, Biocompatible Initiators for TwoPhoton-Induced Polymerization. Chem. Mater. 2014, 26, 3175-3184.

[20] Abdallah M.; Hijazi A.; Graff B.; Fouassier J.P.; Rodeghiero G.; Gualandi A.; Dumur F.; Cozzi P.G.; Lalevée J. Coumarin Derivatives as Versatile Photoinitiators/Photoredox Catalysts for 3D Printing, Polymerization in Water and Photocomposites Synthesis. Polym. Chem. 2019, 10, $872-884$.

[21] Abdallah M.; Hijazi A.; Graff B.; Fouassier J.P.; Dumur F.; Lalevée J. In-silico Development of Photoinitiators for 3D Printing and Composites: Search on the Coumarin Scaffold. Polym. Sci. 2020, Submitted.

[22] Abdallah M.; Hijazi A.; Graff B.; Fouassier J.P.; Dumur F.; Lalevée J. Nitro-Coumarins a High-Performance Scaffold for Near-UV Photoinitiators: Towards New Opportunities in 3D Printing and Composites Technologies. Marcomolecules. 2020, Submitted. 
[23] Monroe B. M.; Weed C. G. Photoinitiators for Free-radical-initiated Photoimaging Systems. Chem. Rev. 1993, 93, 435-448.

[24] Chen Y.; Hong R.T. Photopolymerization of 7,7'-Coumarinyl Polymethylene Dicarboxylates: Fluorescence and Kinetic Study. J. Polym. Sci. Part A: Pol. Chem. 1997, 35, 2999-3008.

[25] Dietlin C.; Schweizer S.; Xiao P.; Zhang J.; Morlet-Savary F.; Graff B.; Fouassier J.P.; Lalevée J. Photopolymerization upon LEDs: New Photoinitiating Systems and Strategies. Polym. Chem. 2015, 6, 3895-3912.

[26] Lalevée J.; Blanchard N.; Tehfe M. A.; Morlet-Savary F.; Fouassier J.P. Green Bulb Light Source Induced Epoxy Cationic Polymerization under Air Using Tris(2,2'bipyridine)ruthenium(II) and Silyl Radicals. Macromolecules 2010, 43, 10191-10195.

[27] Lalevée J.; Blanchard N.; Tehfe M. A.; Peter M.; Morlet-Savary F.; Gigmes D.; Fouassier J.P. Efficient Dual Radical/Cationic Photoinitiator under Visible Light: A New Concept. Polym. Chem. 2011, 2, 1986-1991.

[28] Rehm D.; Weller A. A. Kinetics of Fluorescence Quenching by Electron and H-Atom Transfer. Isr. J. Chem. 1970, 8, 259-271.

[29] Abdallah M.; Le H.; Hijazi A.; Schmitt M.; Graff B.; Dumur F.; Bui T.T.; Goubard F.; Fouassier J.P.; Lalevée J. Acridone Derivatives as High Performance Visible Light Photoinitiators for Cationic and Radical Photosensitive Resins for 3D Printing Technology and for Low Migration Photopolymer Property. Polymer. 2018, 159, 47-58.

[30] Zhang J.; Dumur F.; Xiao P.; Graff B.; Bardelang D.; Gigmes D.; Fouassier J.P.; Lalevée J. Structure Design of Naphthalimide Derivatives: Toward Versatile Photoinitiators for Near- 
UV/Visible LEDs, 3D Printing, and Water-Soluble Photoinitiating Systems. Macromolecules. 2015, 48, 2054-2063.

[31] Xiao P.; Dumur F.; Zhang J.; Fouassier J.P.; Gigmes D.; Lalevée J. Copper Complexes in Radical Photoinitiating Systems: Applications to Free Radical and Cationic Polymerization upon Visible LEDs. Macromolecules. 2014, 47, 3837-3844.

[32] Besisa D. H. A.; Ewais E. M. M.; Ahmed Y. M. Z.; Elhosiny F. I.; Kuznetsov D. V.; Fend T. Densification and Characterization of SiC-AlN Composites for Solar Energy Applications. Renew. Energy. 2018, 129, 201-213.

[33] Grande D. H.; Greist S.; Jessie T.; Daniel J. Reference Module in Materials Science and Materials Engineering, Comprehensive Composite Materials II, Composites in Sports Applications. Elsevier. 2018, 3, 469-526.

[34] Balasubramanian K.; Sultan M.T.H.; Rajeswari N. Sustainable Composites for Aerospace Applications, Manufacturing Techniques of Composites for Aerospace Applications. Woodhead Publishing Series in Compos. Sci. Eng. 2018, 55-67.

[35] Yadav S.; Gangwar S.; Singh S. Micro/Nano Reinforced Filled Metal Alloy Composites: A Review Over Current Development in Aerospace and Automobile Applications. Mater. Today Proceedings. Part E. 2017, 4, 5571-5582.

[36] Komus A.; Beley N. Composite Applications for Ground Transportation. In Comprehensive Composite Materials II; Beaumont P. W. R., Zweben C. H., Eds.; Elsevier. 2018, 3, 420-438.

[37] Fouassier J.P.; Lalevée J. Photoinitiators for Polymer Synthesis, Scope, Reactivity, and Efficiency; Wiley-VCH Verlag: Weinheim, Germany. 2012. 
[38] Zivic N.; Bouzrati-Zerelli M.; Kermagoret A.; Dumur F.; Fouassier J.P.; Gigmes D.; Lalevée

J. Photocatalysts in Polymerization Reactions. Chem.Cat.Chem. 2016, 8, 1617-1631.

[39] Lalevée J.; Fouassier J.P. Dyes and Chromophores in Polymer Science, Wiley-ISTE, London, 2016.

[40] Garra P.; Graff B.; Morlet-Savary F.; Dietlin C.; Becht J.M.; Fouassier J.P.; Lalevée J. Charge Transfer Complexes as Pan-Scaled Photoinitiating Systems: From $50 \mu \mathrm{m}$ 3D Printed Polymers at $405 \mathrm{~nm}$ to Extremely Deep Photopolymerization (31 cm). Macromolecules 2018, 51, 57-70.

[41] Lin, J.T. Efficacy S-formula and Kinetics of Non-oxygen-mediated (Type-I) and Oxygenmediated (Type-II) Corneal Cross-linking. Ophthalmology Research. 2018, 8, 1-11.

[42] Lin J.T.; Liu H.W.; Chen K.T.; Cheng D.C. Modeling the Kinetics, Curing Depth, and Efficacy of Radical-Mediated Photopolymerization: The Role of Oxygen Inhibition, Viscosity, and Dynamic Light Intensity. Front. Chem. 2019, 7, 760-773.

[43] Lin J.T.; Liu H.W.; Chen K.T.; Cheng D.C. Modeling the Optimal Conditions for Improved Efficacy and Crosslink Depth of Photo-Initiated Polymerization. Polymers. 2019, 11, 217-234.

[44] Chiu Y.C.; Lin J.T.; Cheng D.C.; Chen K.T.; Liu H.W. Dual-function Enhancer for NearInfrared Photopolymerization: Kinetic Modeling for Improved Efficacy by Suppressed Oxygen Inhibition. IEEE Access (in press, 2020).

[45] Lin J.T.; Cheng D.C.; Chen K.T.; Liu H.W. Dual-Wavelength (UV and Blue) Controlled Photopolymerization Confinement for 3D-printing: Modeling and Analysis of Measurements. Polymers, 2019, 11, 1819. 
[46] Lin J.T.; Cheng D.C.; Chen K.T.; Chen K.T.; Liu H.W. 3-Wavelength (UV, blue, red) Controlled Photopolymerization: Improved Conversion and Confinement in 3D-Printing. IEEE, 2020, $8,49353-49362$. 


\section{TOC Graphic:}

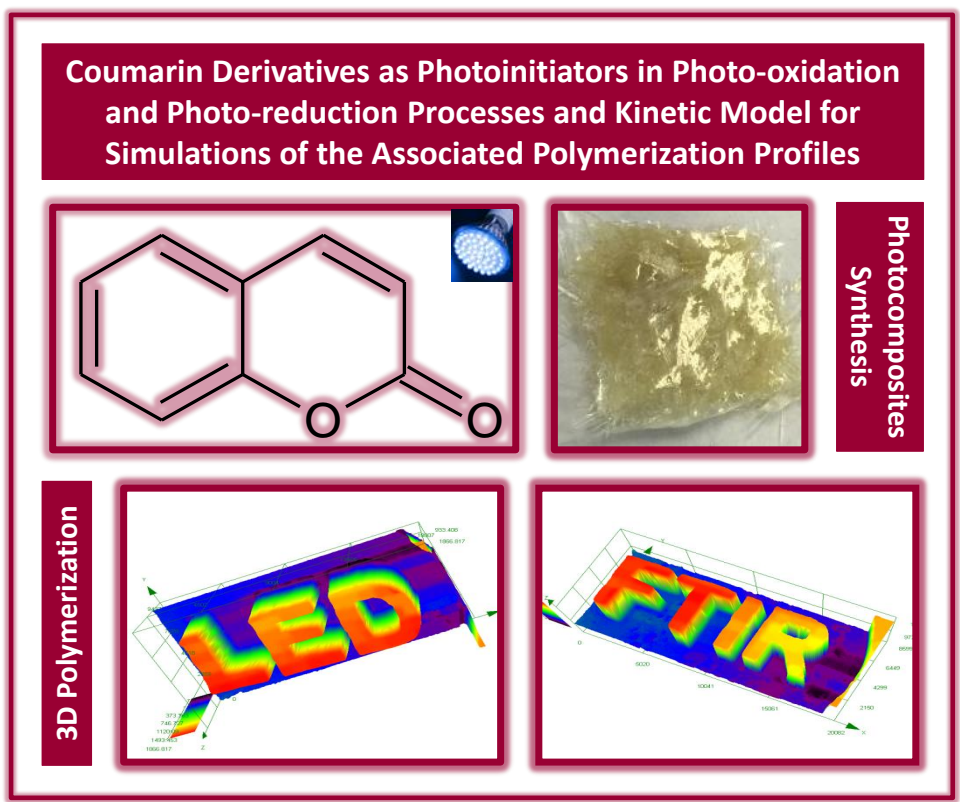

